\title{
Effect of antihistamine-containing syrup on salivary metabolites: an in vitro and in vivo study
}

\section{Tatiana Kelly da Silva Fidalgo(a)} Liana Bastos Freitas-Fernandes ${ }^{(b)}$ Fabio Ceneviva Lacerda Almeida ${ }^{(c)}$ Ivete Pomarico Ribeiro de Souza ${ }^{(b)}$ Ana Paula Valente (c) (iD

(a) Universidade do Estado do Rio de Janeiro - UERJ, School of Dentistry, Department Preventive and Community Dentistry, Rio de Janeiro, RJ, Brazil.

(b) Universidade Federal do Rio de Janeiro UFRJ, School of Dentistry, Department of Pediatric Dentistry and Orthodontics, Rio de Janeiro, RJ, Brazil.

(c) Universidade Federal do Rio de Janeiro UFRJ, National Center of Nuclear Magnetic Resonance, Medical Biochemistry, Rio de Janeiro, RJ, Brazil.

Declaration of Interests: The authors certify that they have no commercial or associative interest that represents a conflict of interest in connection with the manuscript.

\section{Corresponding Author:}

Ana Paula Valente

E-mail:valente.anap@gmail.com

https://doi.org/10.1590/1807-3107bor-2021.vol35.0032

Submitted: June 2, 2020

Accepted for publication: October 22, 2020

Last revision: November 19, 2020
Abstract: This study tested the null hypothesis that antihistaminecontaining syrup does not change salivary metabolites in vitro and in vivo. For the in vitro experiments, saliva from 10 volunteers was mixed with a syrup or pill suspension of loratadine $\left(1 \mathrm{mg} / \mathrm{ml} \mathrm{Claritin}{ }^{\circledR}\right.$, Schering-Plough, Rio de Janeiro, Brazil). For the in vivo experiment, 10 volunteers performed a mouth rinse with $10 \mathrm{~mL}$ of antihistamine syrup (Claritin ${ }^{\circledR}$; Schering-Plough, Rio de Janeiro, Brazil) for 20 seconds and then discarded the rinse water. After 20 seconds, $5 \mathrm{~mL}$ of unstimulated whole saliva was spit into a plastic tube kept on ice. The protein profile of in vitro and in vivo experiments was analyzed using $12 \%$ sodium dodecyl sulfate-polyacrylamide gel electrophoresis. The samples were also analyzed by nuclear magnetic resonance (NMR) spectroscopy, followed by Principal Component Analysis and Wilcoxon test $(p<0.05)$. There were differences in salivary metabolites after syrup interaction. The salivary concentrations of acetate, n-caproate, arginine, glutamate, and lysine among other metabolites were reduced with the syrup in both in vivo and in vitro experiments $(\mathrm{p}<0.05)$, but no differences were observed when the pill suspension was used $(p>0.05)$. Similar changes in metabolite profiles were observed in both in vitro and in vivo experiments. Electrophoresis revealed no difference in the salivary protein pattern. The null hypothesis was rejected because the intake of syrup medicine changes the salivary composition and influences oral homeostasis and susceptibility to oral diseases.

Keywords: Saliva; Anti-Allergic Agents; Proteins; Electrophoresis; Magnetic Resonance Spectroscopy

\section{Introduction}

Allergy is one of the most common causes of respiratory disease, and according to the World Health Organization, asthma kills around 1,000 people daily and affects 339 million. Low- and middle-income countries disproportionally suffer the most severe cases. ${ }^{1,2}$ Antihistamine, an allergy medication, is commonly used alone or in association with pseudoephedrine. Patients with allergies frequently need medication throughout their life, ${ }^{3,4}$ and it is important to assess the effect of these medicines on saliva. 
Human saliva, a complex mixture of proteins and small molecules, performs important and wellrecognized functions that are needed to maintain oral health and the homeostasis of the oral environment. $5,6,7$ Adsorption of salivary metabolites on the oral surface is influenced by tooth anatomy, chemical composition of saliva, and microbial flora and may lead to the development of oral disease, such as caries. ${ }^{8,9}$

Liquid medicines or mouth rinses can interact with saliva components ${ }^{10,11}$ and influence oral homeostasis ${ }^{12,13}$ by promoting biochemical alterations that affect the tooth surface. In addition, the high sucrose concentrations of liquid medicines can increase bacterial growth. ${ }^{14,15}$ Pediatric medicines, in particular, are generally prescribed in a liquid form and include sucrose as a flavor adjunct and preservative. The association between medicinal syrups and the incidence of dental caries is well described in the literature. ${ }^{12,13,14,15,16}$

Among several analytical techniques used for metabolomic studies, nuclear magnetic resonance (NMR) spectroscopy is suitable to identify low-molecular-weight salivary metabolites. ${ }^{7,9,17,18}$ NMR is widely used because it is a non-destructive technique that provides detailed information on molecular structure, both for pure compounds and complex mixtures such as salivary fluid. 7,9,17,19,20

Using high-resolution ${ }^{1} \mathrm{H}-\mathrm{NMR}$ spectroscopy, this study tested the null hypothesis that antihistamine-containing syrup does not change salivary metabolites.

\section{Methodology}

\section{Subjects of the study}

This study was approved by the Local Ethical Committee (64/65-2009 - CEP NESC UFRJ), and written informed consent was obtained from each subject.

The same subjects participated in the in vitro and in vivo studies. Ten volunteers without any systemic disease and allergies were recruited from the Dental School (Universidade Federal do Rio de Janeiro) for in vitro and in vivo experiments. The systemically healthy subjects were 24-30years old (mean age 26.6 years). Subjects who were diagnosed with systemic comorbidities (i.e., obesity, diabetes, renal failure, and Sjogren Syndrome), who had bleeding oral lesions, who were undergoing medicine administration such as antihistamine, or who had taken systemic antibiotics within 6 months prior to saliva sample collection were excluded. The subjects were free of periodontal disease or dental caries, as determined by visual-tactile examination by a single examiner. All volunteers provided informed consent, and the local research ethics committee approved the study.

\section{In vitro experiments}

Whole saliva $(5 \mathrm{~mL})$ was collected in the morning at the same time of the day (8:00 am-10:00 am) to avoid fluctuations in the results due to the circadian saliva cycle. ${ }^{21,22}$ Patients were instructed to expectorate saliva samples into a plastic tube kept on ice. Each patient was instructed to refrain from oral activities, such as eating or drinking (excluding drinking water), as well as to not brush their teeth for 2 hours prior to sample collection. The samples were centrifuged at $10,000 \times g$ for 60 minutes at $4^{\circ} \mathrm{C}$ to remove cells and debris. ${ }^{79,17,18}$ The supernatants were subsequently stored at $-80^{\circ} \mathrm{C}$ until NMR analysis. For in vitro experiments, $1 \mathrm{mg} / \mathrm{ml}$ Claritin ${ }^{\circledR}$ syrup (Schering-Plough, Rio de Janeiro, Brazil) diluted in distilled water at $\mathrm{pH} 7.0$ and mixed with $0.45 \mathrm{~mL}$ saliva was used. This concentration was selected on the basis of a pilot study that demonstrated a similar resonance intensity between in vitro and in vivo experiments (data not shown). Control samples were prepared as described using $5 \%$ distilled water instead of the drug solution. After 20 seconds of incubation, the mixture was centrifuged at 3,000 $\times g$ for 3 minutes and the supernatant was used for NMR analysis. This protocol was according to that in a pilot study, in which no pellet formation was observed.

The second approach used a Claritin ${ }^{\circledR}$ pill (Schering-Plough, Rio de Janeiro, Brazil) that was dissolved in $1 \mathrm{mg} / \mathrm{mL}$ of citric acid (same concentration of the syrup), and after the extraction of loratadine, it was neutralized to $\mathrm{pH} 7.0$ using sodium hydroxide. The suspension was centrifuged at 3,000 $\times g$ for 5 minutes, and the supernatant contained 
loratadine at $\sim 2.61 \mathrm{mM}$. The resultant solution also contained lactose. The pill extract was then mixed with the saliva of a volunteer. The same pill extract was used for all samples. After 20 seconds of incubation, the saliva mixture was centrifuged at 3,000 $\times g$ for 3 minutes and the supernatant was used for NMR analysis. This protocol was according to that in a pilot study, in which no pellet formation was observed.

\section{In vivo experiments}

Ten volunteers performed a mouth rinse with $10 \mathrm{~mL}$ of antihistamine syrup (Claritin ${ }^{\circledR}$; ScheringPlough, Rio de Janeiro, Brazil) for 20 seconds and then discarded the rinse water. This rinse period was according to that in a pilot study (data not shown). After this period, $5 \mathrm{~mL}$ of whole saliva was expectorated from the mouth into a plastic universal tube placed on ice. The volunteers were instructed to rinse their mouth with water and spit it out to remove the residual syrup, and none of them reported any adverse effect. The samples were centrifuged at $10,000 \times g$ and $4^{\circ} \mathrm{C}$ for 60 minutes, and the supernatants were used for NMR analysis. ${ }^{79,17,18}$

\section{Nuclear magnetic resonance analysis}

All samples were prepared by mixing $0.45 \mathrm{~mL}$ of the salivary material with $0.05 \mathrm{~mL}$ of deuterium oxide (Cambridge Isotope Laboratories Inc., Cambridge, USA), which provides a field-frequency lock, and $0.01 \mathrm{~mL}$ of $5 \mathrm{mM}$ sodium 2,2-dimethyl2-silspentane-5-sulfonate solution (DSS; SigmaAldrich, Milwaukee, USA). Deuterium oxide was used as a lock to the magnetic field with the sample (lock), and DSS was used as the chemical shift reference ( $\delta=0.00$ part per million [ppm]).

NMR spectra were acquired using a Bruker $400 \mathrm{MHz}$ Avance spectrometer (Bruker Biospin, Rheinstetten, Germany) equipped with a Bruker 5-mm high-resolution probe operating at a frequency of ${ }^{1} \mathrm{H}$ at $400.13 \mathrm{MHz}$ and a probe temperature of $25^{\circ} \mathrm{C}$. Carr-Purcell-Meiboom-Gill pulse sequence for ${ }^{1} \mathrm{H}$ spectrum and ${ }^{1} \mathrm{H}-{ }^{1} \mathrm{H}$ total correlation spectroscopy experiments with acquisition parameters of $70 \mathrm{~ms}$ mixing time and $2048 \times 256$ points were performed according to Fidalgo et al. ${ }^{7,9}$ NMR signals were determined over a range of frequencies defined by the resonance difference between a specific peak and a standard (DSS), expressed in ppm. After spectra acquisition, edge effects were evaluated by overlaying all spectra using Topspin (Bruker Biospin). In brief, each chemically distinct hydrogen nucleus of low-molecular-weight metabolites from salivary samples produce an NMR signal that is measured as a chemical shift, represented by ppm, which characterizes a metabolite. ${ }^{23}$ The assignment strategy of the metabolites in the chemical shifts included the use of the Human Metabolome database (http://www.hmdb.ca/), assignment strategies used in previous studies, ${ }^{79,17,18}$ and ${ }^{1} \mathrm{H}_{-}^{-1} \mathrm{H}$ total correlation spectroscopy experiments.

\section{Electrophoresis analysis}

To evaluate salivary protein interaction with pill or syrup compositions, mixtures of salivary samples from three subjects were analyzed by sodium dodecyl sulfate-polyacrylamide gel electrophoresis, performed according to the method by Laemmli, ${ }^{24}$ using $12 \%$ running gel and $4 \%$ stacking gel, and the samples were stained using Coomassie blue.

\section{Statistical analyses}

Metabolite intensities were determined using the statistical program AMIX (Bruker Biospin). Saliva spectra were compared before and after antihistamine syrup treatment. Each spectral dataset was normalized to the total sum of the integrals to compensate partially for differences in concentrations, and the matrix was normalized by scaling the dataset using Pareto scaling. ${ }^{25}$ Each NMR spectrum was reduced to a smaller number of variables, calculated by integrating regions of equal bucket size of $0.02 \mathrm{ppm}$. The water region was excluded to eliminate variation. Regions of syrup and pill suspension components, i.e., 0.80$1.88,2.33-4.03,4.50-5.50,6.95-7.95$, and 8.27-8.74 ppm, were also excluded. The datasets were stored in a matrix $E$ with 35 rows ( 35 data sets from the samples: 10 before drug application, 10 after in vitro syrup drug application, 10 after in vivo syrup drug application, and 5 after in vitro pill suspension) and 335 columns ( 335 chemical shifts). The bucket tables 
were normalized using the sum of intensities, and the data were submitted to the Pareto scaling method ${ }^{25}$, before applying the partial least squares-discriminant analysis (PLS-DA) method. PLS-DA used the initial input variables of each group that were stored in the y-table (0 and 1) and was performed using Metaboanalyst 3.0 software (www.metaboanalyst. $\mathrm{ca} /$ MetaboAnalysts). ${ }^{26}$

Metaboanalyst 3.0 software was also used to determine the predictive performance of the models; in addition, each model was evaluated using $Q^{2}, R^{2}$, and accuracy (ACC), for the purpose of cross-validation. ${ }^{27}$

Further, the intensity of each peak corresponding to the chemical shifts was tabulated using Statistical Package for the Social Sciences 20.0 (SPSS Inc., Chicago, USA) and subjected to normality analysis by applying Shapiro-Wilk test. Wilcoxon test was used to evaluate the differences in metabolite intensities before and after the antihistamine syrup or pill. The significance level was set at $5 \%$. The power analysis was calculated on the basis of the acetate peak because this metabolite appeared frequently in the obtained spectra and is unambiguously assigned singlet. For this calculation, the means and standard deviations of the intensities (arbitrary unities) and the sample size of each group (syrup in in vivo mixture, syrup in in vitro mixture, and pill interaction) were obtained. The power analysis is capable of measuring the effect size that can be detected using a given sample size. For this purpose, a confidence interval of $95 \%$ was adopted and a two-tailed test using OpenEpi 3.04.04 software was performed.

\section{Results}

We used two different experimental strategies: in vitro and in vivo. In vitro experiments were performed by incubating whole saliva and antihistaminecontaining syrup in a plastic tube. In vivo experiments required each patient to rinse with a medicinal solution prior to saliva collection. After 20 seconds, the subject expectorated the mixture of medicine and saliva. After centrifugation, each mixture was analyzed by NMR. Figure 1 illustrates the whole saliva ${ }^{1} \mathrm{H}$ NMR spectra as well as resonance intensity differences before and after drug application for in vitro and in vivo experiments. For statistical analyses, the water region was excluded to eliminate variation. To avoid resonances from the syrup and pill components, the following regions were also excluded: $0.80-1.88,2.33-4.03,4.50-5.50,6.95-7.95$, and 8.27-8.74.

Figure 2 shows the PLS-DA plot of ${ }^{1} \mathrm{H}$ NMR results of saliva samples with and without antihistaminic mixture with the syrup or pill. The percentage of variance in Component 1 (CP1) was $29.9 \%$, and Component 2 (CP2) was $28.6 \%$. The accuracy was $85.71 \%$, $\mathrm{R}^{2}$ was $94.79 \%$, and $\mathrm{Q}^{2}$ was $69.15 \%$. The syrup interacted with saliva in both the in vitro and in vivo experiments. The differences in metabolites were similar regardless of the protocol used.

To understand the differences, we determined which metabolite was modified in the presence of the syrup. The in vitro and in vivo experiments show similar changes in salivary metabolite levels. The intensity of resonances from components such as acetate, amino-butyrate, arginine, glutamate, lysine, $n$-caproate, proline, iso-caproate, and isoleucine was statistically significant $(p<0.05)$. Resonance assignments of these salivary metabolite components before and after antihistamine application are shown in Table. Some liquid medicines, such as the antihistamine syrup used in this study, are chemically stable at low $\mathrm{pH}$, and citric acid is generally used for this purpose. ${ }^{13}$ Citric acid commonly acts as a salivary-stimulating agent by increasing salivary flow; thus, some metabolites could be diluted in saliva. ${ }^{11,25}$ However, our study demonstrated that both in vitro and in vivo drug application resulted in a reduction of specific metabolite concentrations. For this reason, we suggest that the antihistamine syrup also interacts with specific metabolites, reducing their concentrations in the saliva. The power analysis demonstrated an effect size of $100 \%$ for the syrup in the in vivo experiment, $99.99 \%$ for the mixture in the in vivo experiment, and $4.24 \%$ for pill interaction.

The electrophoresis analysis revealed no differences in the salivary protein pattern between control samples 


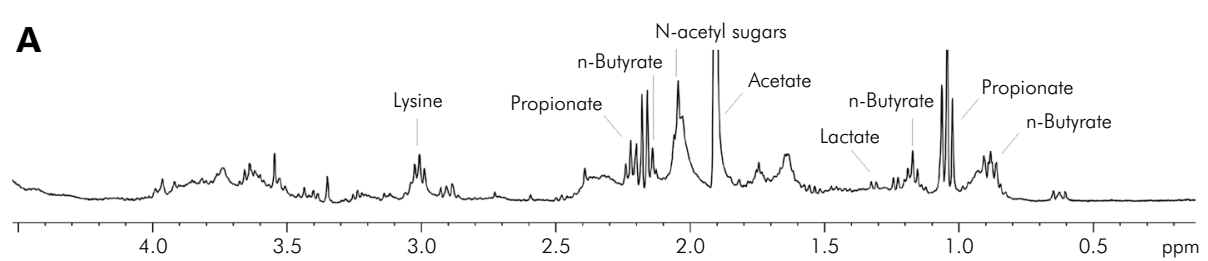

B
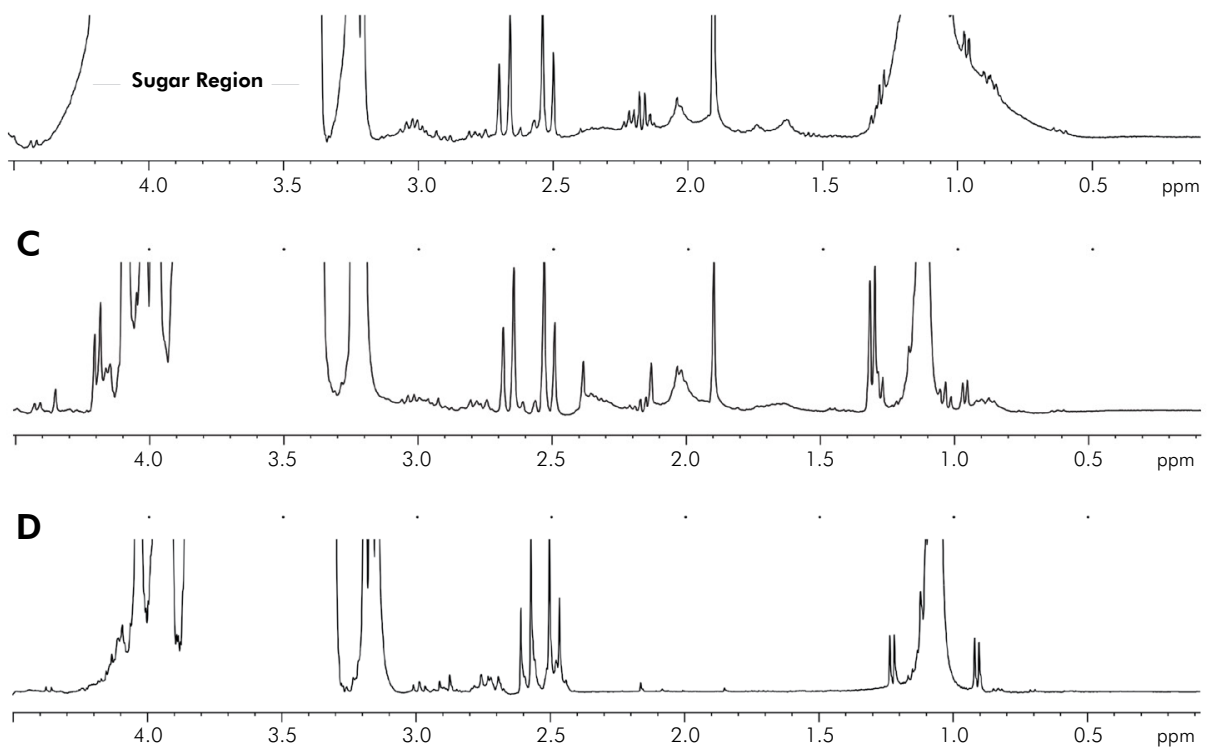

Figure 1. Representative 'H NMR spectra of whole saliva before and after the administration of antihistamine syrup or pill mixture (0-4.5 ppm). A: Spectrum of whole saliva; B: Spectrum with in vitro syrup mixture; C: Spectrum after in vivo syrup experiment (rinse); D: Spectrum with in vitro pill suspension.

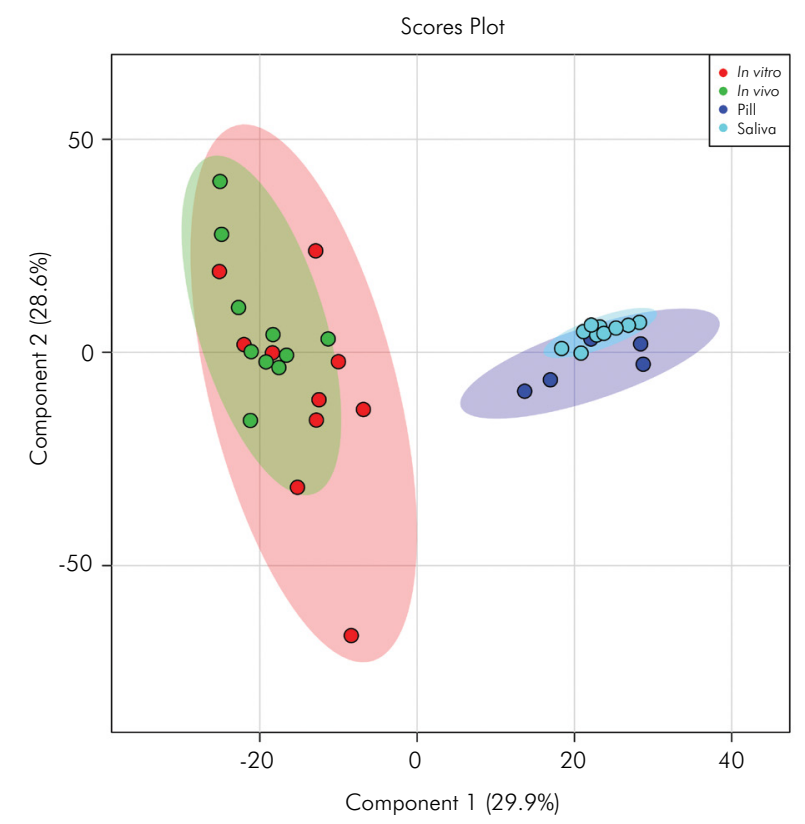

Figure 2. Two-component Principal Component Analysis model showing sample clustering of saliva without any medicine (black) and after treatment with antihistamine syrup in vitro (blue) and in vivo (green). In vitro treatment with the antihistamine pill extract is shown in red. The percentage of variance captures by $36.38 \%$ and Principal Component 2 (PC2) was $25.81 \%$. 
Table. Resonance assignments of salivary metabolite components before and after application of antihistamine mixture.

\begin{tabular}{|c|c|c|c|c|c|c|c|}
\hline Metabolites & $\begin{array}{l}\text { 'H Chemical Shift } \\
\text { (ppm) }\end{array}$ & Multiplicity* & Assignment & Syrup ${ }^{a}$ & $\begin{array}{l}\text { Syrup } \\
\text { in vivo }^{\text {b }}\end{array}$ & $\begin{array}{c}\text { Pill } \\
\text { interaction }\end{array}$ & $p$-value** \\
\hline \multirow{3}{*}{ Acetate } & \multirow{3}{*}{1.92} & \multirow{3}{*}{ s } & \multirow{3}{*}{0} & \multirow{3}{*}{$\downarrow$} & \multirow{3}{*}{$\downarrow$} & \multirow{3}{*}{ NC } & $<0.01^{\circ}$ \\
\hline & & & & & & & $<0.01^{\mathrm{b}}$ \\
\hline & & & & & & & $0.94^{c}$ \\
\hline \multirow{3}{*}{ Aminobutyrate } & \multirow[t]{3}{*}{$1.88,2.29$} & $m, \dagger$ & $\beta-\mathrm{CH}_{2}, \alpha-\mathrm{CH}_{2}$ & \multirow{3}{*}{$\downarrow$} & \multirow{3}{*}{$\downarrow$} & \multirow{3}{*}{ NC } & $<0.01^{\circ}$ \\
\hline & & \multirow{2}{*}{$\dagger$} & \multirow[t]{2}{*}{$\gamma-\mathrm{CH}_{2}$} & & & & $<0.01^{b}$ \\
\hline & & & & & & & $0.92^{c}$ \\
\hline \multirow{3}{*}{ Arginine } & \multirow{3}{*}{$\begin{array}{c}1.71,1.93,3.25 \\
3.68\end{array}$} & \multirow{3}{*}{$\begin{array}{l}m, m, \\
t, t\end{array}$} & \multirow{3}{*}{$\begin{array}{l}\gamma-\mathrm{CH}, \beta-\mathrm{CH}_{2} \\
\delta-\mathrm{CH} 2, \alpha-\mathrm{CH}\end{array}$} & \multirow{3}{*}{$\downarrow$} & \multirow{3}{*}{$\downarrow$} & \multirow{3}{*}{ NC } & $<0.01^{\circ}$ \\
\hline & & & & & & & $<0.01^{b}$ \\
\hline & & & & & & & $<0.64^{c}$ \\
\hline \multirow{3}{*}{ Glutamate } & \multirow{3}{*}{$\begin{array}{c}2.10,2.37 \\
3.79\end{array}$} & \multirow{3}{*}{$\begin{array}{c}m, m, \\
+\end{array}$} & \multirow{3}{*}{$\begin{array}{c}\beta-\mathrm{CH}_{2}, \gamma-\mathrm{CH}_{2}, \\
\alpha-\mathrm{CH}\end{array}$} & \multirow{3}{*}{$\downarrow$} & \multirow{3}{*}{$\downarrow$} & \multirow{3}{*}{ NC } & $<0.01^{\circ}$ \\
\hline & & & & & & & $<0.01^{\mathrm{b}}$ \\
\hline & & & & & & & $0.25^{c}$ \\
\hline \multirow{3}{*}{ Lysine } & \multirow{3}{*}{$\begin{array}{c}1.49,1.73,1.90 \\
3.01,3.76\end{array}$} & $m, m$ & $\gamma-\mathrm{CH}_{2}, \delta-\mathrm{CH}_{2}$ & \multirow{3}{*}{$\downarrow$} & & & $<0.01^{\circ}$ \\
\hline & & $m, t$ & $\beta-\mathrm{CH}_{2,},-\mathrm{CH}_{2 \prime}$ & & $\downarrow$ & NC & $0.03^{b}$ \\
\hline & & $\dagger$ & $\alpha-\mathrm{CH}$ & & & & $0.47^{c}$ \\
\hline & & $\mathrm{t}, \mathrm{m}$, & $-\mathrm{CH} 3, \delta-\mathrm{CH}_{2}^{\prime} \mathrm{s}$ & & & & $<0.01^{\circ}$ \\
\hline n-caproate & $\begin{array}{c}0.83,1.35,1.58, \\
2.15\end{array}$ & $m, \dagger$ & $\beta-\mathrm{CH}_{2}, \alpha-\mathrm{CH}_{2}$ & $\downarrow$ & $\downarrow$ & NC & $<0.01^{b}$ \\
\hline & & & & & & & $0.32^{c}$ \\
\hline & $2.07,2.07$ & $m, m$ & $\alpha-\mathrm{CH}_{2}, \beta-\mathrm{CH}_{2}$ & & & & $<0.01^{a}$ \\
\hline Proline & $2.35,3.40$ & $m, m$, & $\beta-\mathrm{CH}_{2}, \delta-\mathrm{CH}_{2}$ & $\downarrow$ & $\downarrow$ & NC & $<0.01^{b}$ \\
\hline & 4.16 & & $\alpha-\mathrm{CH}_{2}$ & & & & $0.76^{c}$ \\
\hline & & $d, m$, & & & & & $0.27^{a}$ \\
\hline Iso-caproate & $\begin{array}{c}0.91,1.55,1.58, \\
2.15\end{array}$ & & $\delta-\mathrm{CH}_{3}{ }^{\prime} \mathrm{s}, \beta-\mathrm{CH}_{2}, \gamma-\mathrm{CH}_{2}, \alpha-\mathrm{CH}_{2}$ & $\downarrow$ & $\downarrow$ & NC & $<0.01^{b}$ \\
\hline & & & & & & & $0.98^{c}$ \\
\hline & & $t, d$ & $\mathrm{CH} 3, \beta-\mathrm{CH}_{2}$ & & & & $<0.01^{a}<0.01^{b}$ \\
\hline Isoleucine & $\begin{array}{c}0.94,1.01,1.47 \\
1.99,3.68\end{array}$ & $m, m$ & $-\mathrm{CH}_{2}, \beta-\mathrm{CH}$ & $\downarrow$ & $\downarrow$ & NC & $0.78^{c}$ \\
\hline & & d & $\alpha-\mathrm{CH}$ & & & & \\
\hline
\end{tabular}

${ }^{*}$ Multiplicity: $s$ - singlet, $d$ - duplet, $t$ - triplet, $q$ - quadruplet; ${ }^{* *}$ Wilcoxon test; $p<0.05$. $p$-values indicate the comparisons with the control group; NC: no change.

and after mixture of the samples with the syrup or pill suspension (Figure 3).

\section{Discussion}

In our study, high-resolution ${ }^{1} \mathrm{H}$ NMR spectra demonstrated changes in metabolite levels after application of antihistamine syrup using both in vitro and in vivo methods.

Principal Component Analysis is often used in metabolomic studies to classify subjects with different conditions. ${ }^{28,29,30}$ In our study, principal component analysis illustrated differences in the metabolite profile of saliva before and after application of antihistamine syrup, using both in vitro and in vivo methods. Additionally, the analysis demonstrated that the pill suspension assay induced no statistically significant changes compared with the control group. Therefore, our experiments indicated that the active drug, loratadine, did not cause changes in salivary metabolite levels. We also evaluated the antihistamine pill in citric acid, the same acid found 

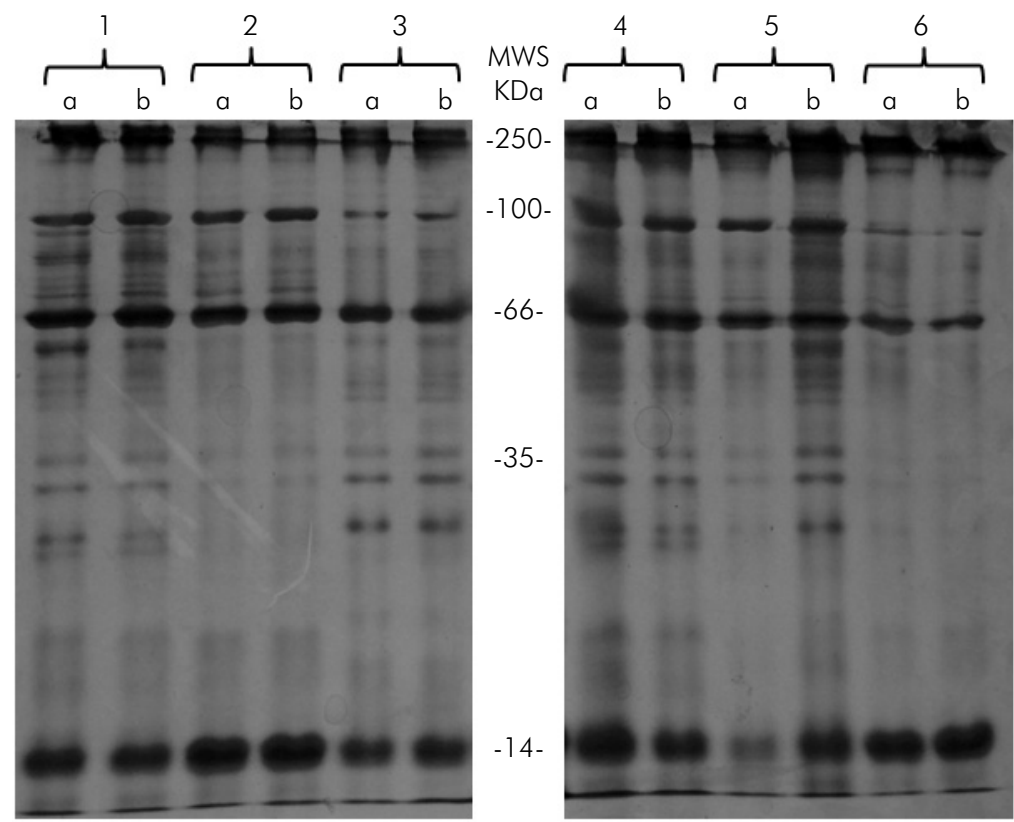

The letter " $a$ " indicates control grou, the $1 b, 2 b$, and $3 b$ are the salivary protein pattern after mixture with pill suspension and $4 b, 5 b$, and $5 b$ after mixture with syrup.

Figure 3. Electrophoresis demonstrating no difference among groups.

in the syrup, and we observed no difference in the saliva component. The differences in metabolites were similar regardless of the protocol used. Furthermore, the changes in concentration of metabolites were related to the syrup composition because the same experiment performed with the antihistamine pill did not change the salivary composition. We conclude that the changes in saliva are related to the syrup formulation. Although 20 seconds is sufficient time to swallow a liquid medicine, the clearance of a liquid in the oral cavity takes approximately 5-10 min. ${ }^{31}$ Further, the duration of 20 seconds was used according to that in a pilot study.

The clearance of sucrose in the oral cavity is slow, and sucrose can be used by oral biofilms for energetic metabolism, producing organic acids. ${ }^{32}$ Our results indicate that children using antihistamine syrup should be encouraged to brush their teeth after use. To minimize tooth damage in children who frequently use antihistamine syrups, oral hygiene should be practiced after administration of liquid medicines. ${ }^{33,34}$ This procedure will remove sugar contained in the syrup and prevent the development of dental caries. Administration of syrup-based medicines at night should be avoided because salivary flow is naturally lower and its protective capacity is reduced. ${ }^{33,35}$

The interaction of salivary proteins with oral medicines has been previously studied. ${ }^{10,36,37}$ In contrast, limited information is available regarding changes in low-molecular-weight metabolites after interaction with oral medicines. A study using NMR demonstrated differences in the metabolic profile of human saliva before and after treatment with a mouth rinse. ${ }^{30}$ The chemometric approach could identify alterations in metabolites such as glutamine, proline, leucine, valerate, acetoacetate, and arginine.

The authors suggested that this type of study design could benefit further investigation in the metabolomic field. In our study, some organic acids, such as acetate, n-caproate, and iso-caproate, also had reduced concentrations after mixing with antihistamine syrup. Metabolites such as acetate, $\mathrm{n}$-caproate, and iso-caproate are probably from microorganism metabolism. ${ }^{79}$ These salivary metabolites decrease the salivary $\mathrm{pH}$ of dental plaque, and if this $\mathrm{pH}$ reaches the critical $\mathrm{pH}$, it can lead to enamel demineralization. ${ }^{38}$ Although these metabolites were immediately reduced after syrup interaction, it is important to point out that 
syrup contains high levels of sugar, and therefore, it potentially increases organic acids with time.

Similarly, the concentrations of amino acids such as arginine, glutamate, lysine, isoleucine, aminobutyrate, and proline were significantly lower after antihistamine syrup application, as determined using in vitro and in vivo methods. The role of amino acids in oral diseases remains unclear. Massoudi et al. ${ }^{39}$ suggested that the presence of various amino acids prevents bacterial growth. Amino acids can also exert a beneficial effect against dental caries owing to the enhancement of $\mathrm{NH}_{4}{ }^{+}$. Furthermore, free amino acids exhibit different chemical properties and their combination can produce proteins with a large variety of functions in the oral cavity; ${ }^{40}$ thus, their functions in the oral cavity must be thoroughly understood.

In the present study, the local effect of antihistaminecontaining syrup on salivary metabolites was evaluated. The antihistamine syrup loratadine presents a pKa of $\sim 4.33$ (https://hmdb.ca/metabolites/ HMDB0005000) and is a weakly ionizable base with $\mathrm{pH}$-dependent solubility, and its solubility decreases exponentially with an increase in $\mathrm{pH}$. Therefore, loratadine is more soluble in the stomach, which has at lower $\mathrm{pH}$ than the oral mucosa, which has a $\mathrm{pH}$ of $\sim 7.0{ }^{41}$ It is important to highlight that not all drugs can be efficiently absorbed through the oral mucosa. ${ }^{42}$ For example, the systemic bioavailabilities of peptides and proteins are typically less than $5 \%$ of the administered dose with transmucosal delivery because of the physicochemical barrier of the oral mucosa, which contains enzymes that break down peptides. In addition, the barrier properties of the epithelium result in the oral mucosa being an efficient barrier to drug penetration, allowing only small quantities of a drug to penetrate. Furthermore, oral mucosal delivery is suitable only for drugs with a high potency. These layers provide a unique challenge for drug delivery via the oral mucosa. ${ }^{42}$

A limitation of this study was the population studied. The antihistamine syrup is often used by children; however, in this study, for the first time, we aimed to analyze and compare the effects of antihistamine both in vitro and in vivo. Therefore, a young adult population was selected for this purpose because children have a limited ability to spit. There is limited information available regarding the differences between the low-molecularweight metabolites in saliva in children and those in the adult population. However, Fidalgo et al. ${ }^{7}$ demonstrated differences in metabolites based on phases of life, ages, and different dentitions. The authors demonstrated that individuals with permanent dentition (older children) presented higher levels of butyrate, ambiguous assignment, lysine, sugar region, and phenylalanine and propionate in comparison to primary dentition (younger children). In addition, Ellul et al. ${ }^{43}$ identified differences in the concentration of specific metabolites in the serum between children and adults. These findings indicate that the effect of antihistamine-containing syrup in salivary metabolites from a child population can be different from the data reported here; therefore, further studies in a younger population are needed.

In vitro studies are often difficult to correlate with clinical data because of the complex environment of the human saliva. ${ }^{5}$ In our study, the in vitro and in vivo interactions between human salivary components and antihistamine syrup were similar. Therefore, our in vitro assays were validated and could be used to study the interaction of other medicines with salivary metabolites. In addition, we found that NMR is a reliable method to study small molecules.

\section{Conclusions}

The null hypothesis was rejected because the antihistamine syrup altered the salivary metabolite profile. The observed changes are likely related to syrup formulation rather than the active component loratadine. Similar changes in metabolite profiles were observed in both in vitro and in vivo experiments.

\section{Acknowledgments}

The authors acknowledge the Conselho Nacional de Desenvolvimento Científico e Tecnológico (CNPq), Fundação Carlos Chagas Filho de Amparo à Pesquisa do Estado do Rio de Janeiro (FAPERJ), Centro Nacional de Ressonância Magnética Nuclear (CNRMN), and Instituto Nacional de Ciência and Tecnologia de Biologia Estrutural e Bioimagem (InBEB) for their financial support. 


\section{References}

1. Disease GB, Injury I, Prevalence C; GBD 2016 Disease and Injury Incidence and Prevalence Collaborators. Global, regional, and national incidence, prevalence, and years lived with disability for 328 diseases and injuries for 195 countries, 1990-2016: a systematic analysis for the Global Burden of Disease Study 2016. Lancet. 2017 Sep;390(10100):1211-59. https://doi.org/10.1016/S0140-6736(17)32154-2

2. World Health Organization - WHO. Asthma. 2020 May20 [cited 2020 Aug 20]. Available from: https://www.who.int/news-room/factsheets/detail/asthma

3. Fumagalli F, Baiardini I, Pasquali M, Compalati E, Guerra L, Massacane P, et al. Antihistamines: do they work? Further well-controlled trials involving larger samples are needed. Allergy. 2004;59 Suppl 78:74-8. https://doi.org/10.1111/j.1398-9995.2004.00573.x

4. Moinuddin R, Tineo M, Maleckar B, Naclerio RM, Baroody FM. Comparison of the combinations of fexofenadine-pseudoephedrine and loratadine-montelukast in the treatment of seasonal allergic rhinitis. Ann Allergy Asthma Immunol. 2004 Jan;92(1):73-9. https://doi.org/10.1016/S1081-1206(10)61713-9

5. Humphrey SP, Williamson RT. A review of saliva: normal composition, flow, and function. J Prosthet Dent. 2001 Feb;85(2):162-9. https://doi.org/10.1067/mpr.2001.113778

6. Lukacs JR, Largaespada LL. Explaining sex differences in dental caries prevalence: saliva, hormones, and "life-history" etiologies. Am J Hum Biol. 2006 Jul-Aug;18(4):540-55. https://doi.org/10.1002/ajhb.20530

7. Fidalgo TK, Freitas-Fernandes LB, Angeli R, Muniz AM, Gonsalves E, Santos R, et al. Salivary metabolite signatures of children with and without dental caries lesions. Metabolomics. 2013;9(3):657-66. https://doi.org/10.1007/s11306-012-0484-7

8. Siqueira WL, Helmerhorst EJ, Zhang W, Salih E, Oppenheim FG. Acquired enamel pellicle and its potential role in oral diagnostics. Ann N Y Acad Sci. 2007 Mar;1098(1):504-9. https://doi.org/10.1196/annals.1384.023

9. Fidalgo TK, Freitas-Fernandes LB, Almeida FC, Valente AP, Souza IP. Longitudinal evaluation of salivary profile from children with dental caries before and after treatment. Metabolomics. 2015;11(3):583-93. https://doi.org/10.1007/s11306-014-0717-z

10. Freitas-Fernandes LB, Rundegren J, Arnebrant T, Glantz PO; Liana Bastos Freitas-Fernandes, Jan. Delmopinol hydrochloride- and chlorhexidine digluconate-induced precipitation of salivary proteins of different molecular weights. Acta Odontol Scand. 1998 Feb;56(1):2-8. https://doi.org/10.1080/000163598422983

11. Van Steijn GJ, Amerongen AV, Veerman EC, Kasanmoentalib S, Overdijk B. Effect of periodontal treatment on the activity of chitinase in whole saliva of periodontitis patients. J Periodontal Res. 2002 Aug;37(4):245-9. https://doi.org/10.1034/j.1600-0765.2002.00330.x

12. Costa CC, Almeida IC, Costa Filho LC. Erosive effect of an antihistamine-containing syrup on primary enamel and its reduction by fluoride dentifrice. Int J Paed Dent. 2006 May;16(3):174-80. https://doi.org/10.1111/j.1365-263X.2006.00713.x

13. Maguire A, Baqir W, Nunn JH. Are sugars-free medicines more erosive than sugars-containing medicines? An in vitro study of paediatric medicines with prolonged oral clearance used regularly and long-term by children. Int J Paed Dent. 2007 July;17(4):231-8. https://doi.org/10.1111/i.1365-263X.2007.00826.x

14. Grenby TH. The effect of glucose syrup on dental caries in the rat. Caries Res. 1972;6(1):52-69. https://doi.org/10.1159/000259770

15. Shaw L, Glenwright HD. The role of medications in dental caries formation: need for sugar-free medication for children. Pediatrician. 1989;16(3-4):153-5.

16. Costa CC, Almeida IC, Costa Filho LC, Oshima HM. Morphology evaluation of primary enamel exposed to antihistamine and fluoride dentifrice: in vitro study. Gen Dent. 2006 Jan-Feb;54(1):21-7.

17. Almeida PA, Fidalgo TK, Freitas-Fernandes LB, Almeida FC, Souza IP, Valente AP. Salivary metabolic profile of children and adolescents after hemodialysis. Metabolomics. 2017;13(11):141. https://doi.org/10.1007/s11306-017-1283-y

18. Oliveira LR, Martins C, Fidalgo TK, Freitas-Fernandes LB, Torres RO, Soares AL, et al. Salivary metabolite fingerprint of type 1 Diabetes in young children. J Proteome Res. 2016 Aug;15(8):2491-9. https://doi.org/10.1021/acs.jproteome.6b00007

19. Lindon JC, Holmes E, Nicholson JK. Metabonomics techniques and applications to pharmaceutical research \& development. Pharm Res. 2006 Jun;23(6):1075-88. https://doi.org/10.1007/s11095-006-0025-z

20. Lins AP, Furlan M, Gastmans JP, Emerenciano VP. [Application of artificial intelligence techniques in organic chemistry. Study, by computer, of NMR 13C of steroids]. An Acad Bras Cienc. 1991 Jun;63(2):141-53. Portuguese.

21. Dallmann R, Viola AU, Tarokh L, Cajochen C, Brown SA. The human circadian metabolome. Proc Natl Acad Sci USA. 2012 Feb;109(7):2625-9. https://doi.org/10.1073/pnas.1114410109

22. Dawes C. Circadian rhythms in human salivary flow rate and composition. J Physiol. 1972 Feb;220(3):529-45. https://doi.org/10.1113/iphysiol.1972.sp009721

23. Dona AC, Kyriakides M, Scott F, Shephard EA, Varshavi D, Veselkov K, et al. A guide to the identification of metabolites in NMR-based metabonomics/metabolomics experiments. Comput Struct Biotechnol J. 2016;14:135-153. https://doi.org/10.1016/i.csbj.2016.02.005 
Título resumido título resumido título resumido título resumido título resumido título resumido título resumido título resumido

24. Laemmli UK. Cleavage of structural proteins during the assembly of the head of bacteriophage T4. Nature. 1970 Aug;227(5259):680-5. https://doi.org/10.1038/227680a0

25. Ramadan Z, Jacobs D, Grigorov M, Kochhar S. Metabolic profiling using principal component analysis, discriminant partial least squares, and genetic algorithms. Talanta. 2006 Feb;68(5):1683-91. https://doi.org/10.1016/i.talanta.2005.08.042

26. Xia J, Sinelnikov IV, Han B, Wishart DS. MetaboAnalyst 3.0: making metabolomics more meaningful. Nucleic Acids Res. 2015 Jul;43 W1:W251-7. https://doi.org/10.1093/nar/gkv380

27. Velzen EJ, Westerhuis JA, Duynhoven JP, Dorsten FA, Hoefsloot HC, Jacobs DM, et al. Multilevel data analysis of a crossover designed human nutritional intervention study. J Proteome Res. 2008 Oct;7(10):4483-91. https://doi.org/10.1021/pr800145i

28. Grootveld M, Silwood CJ. 1 H NMR analysis as a diagnostic probe for human saliva. Biochem Biophys Res Commun. 2005 Apr;329(1):1-5. https://doi.org/10.1016/i.bbrc.2005.01.112

29. Lemanska A, Grootveld M, Silwood CJ, Brereton RG. Chemometric variance analysis of $1 \mathrm{H}$ NMR metabolomics data on the effects of oral rinse on saliva. Metabolomics. 2012;8(1):64-80. https://doi.org/10.1007/s11306-011-0358-4

30. Wilson CG, Washington NC, Peach J, Murray GR, Kennerley J. The behaviour of fast-dissolving dosage from (Expidet) followed by $\gamma$-scintigraphy. Int J Pharm. 1987;40:119-23.

31. Paes Leme AF, Koo H, Bellato CM, Bedi G, Cury JA. The role of sucrose in cariogenic dental biofilm formation: new insight. J Dent Res. 2006 Oct;85(10):878-87. https://doi.org/10.1177/154405910608501002

32. Neves BG, Farah A, Lucas E, Sousa VP, Maia LC. Are paediatric medicines risk factors for dental caries and dental erosion? Community Dent Health. 2010 Mar;27(1):46-51.

33. Subramaniam P, Nandan N. Cariogenic potential of pediatric liquid medicaments: an in vitro study. J Clin Pediatr Dent. 2012;36(4):357-62. https://doi.org/10.17796/jcpd.36.4.nt11584612462+84

34. Dawes C. Salivary flow patterns and the health of hard and soft oral tissues. J Am Dental Assoc. 2008; 139 Suppl(18S-24S. https://doi.org/10.14219/jada.archive.2008.0351

35. Freitas-Fernandes LB, Rundegren J, Arnebrant T, Glantz PO. Characterization of the binding of delmopinol to salivary precipitates. Braz Dent J. 2001 Set-Dec;12(3):173-7.

36. Santos $O$, Lindh L, Halthur T, Arnebrant T. Adsorption from saliva to silica and hydroxyapatite surfaces and elution of salivary films by SDS and delmopinol. Biofouling. 2010 Aug;26(6):697-710. https://doi.org/10.1080/08927014.2010.506609

37. Qu H, Vasiliev AL, Aindow M, Wei M. Incorporation of fluorine ions into hydroxyapatite by a pH cycling method. J Mater Sci Mater Med. 2005 May; 16(5):447-53. https://doi.org/10.1007/s10856-005-6985-4

38. Masoudi Rad H, Rabiei M, Sobhani A, Sadegh Khanjani M, Rahbar Taramsar M, Kazemnezhad Leili E. Free amino acids in stimulated and unstimulated whole saliva: advantages or disadvantages. J Oral Rehabil. 2014 Oct;41(10):759-67. https://doi.org/10.1111/joor.12197

39. Pedersen AML, Belstrom D. The role of natural salivary defences in maintaining a healthy oral microbiota. J Dent. 2019 Jan;80(Suppl 1):S3-S12. https://doi.org/10.1016/i.jdent.2018.08.010

40. Elkomy MH, El Menshawe SF, Abou-Taleb HA, Elkarmalawy MH. Loratadine bioavailability via buccal transferosomal gel: formulation, statistical optimization, in vitro/in vivo characterization, and pharmacokinetics in human volunteers. Drug Deliv. 2017 Nov;24(1):781-91. https://doi.org/10.1080/10717544.2017.1321061

41. Zhang $\mathrm{H}$, Zhang J, Streisand JB. Oral mucosal drug delivery: clinical pharmacokinetics and therapeutic applications. Clin Pharmacokinet. 2002;41(9):661-80. https://doi.org/10.2165/00003088-200241090-00003

42. Ellul S, Wake M, Clifford SA, Lange K, Würtz P, Juonala M, et al. Metabolomics: population epidemiology and concordance in Australian children aged 11-12 years and their parents. BMJ Open. 2019 Jul;9 Suppl 3:106-17. https://doi.org/10.1136/bmjopen-2017-020900 